\title{
Measurement Research on Commodity Market Segmentation in the Pearl River Delta
}

\author{
Longfang Chen ${ }^{1,2, *}$ \\ ${ }^{1}$ Jilin University, Northeast Asian Studies College, Changchun, Jilin 130012, China \\ ${ }^{2}$ Zhuhai College of Science and Technology, Zhuhai, Guangdong 519041, China \\ *Corresponding author. Email: longfang0603@yeah.net
}

\begin{abstract}
This article uses the relative price method to calculate the commodity market segmentation index of the Pearl River Delta cities from 2000 to 2017, revealing the evolution trend of the Pearl River Delta regional market segmentation. The results show that the commodity market segmentation index of the Pearl River Delta from 2000 to 2017 showed an overall downward trend with slight fluctuations in some specific years. The phenomenon of commodity market segmentation in Zhongshan, Zhuhai, and Huizhou was the most serious, the market segmentation degree of Zhaoqing and Jiangmen was the lowest, Shenzhen's continued downward trend was the most obvious, and the market segmentation degree on the west coast was more serious than that of the east coast.
\end{abstract}

Keywords: Pearl River Delta, Commodity market, Market segmentation index.

\section{INTRODUCTION}

Since the reform and opening up for 40 years, the Pearl River Delta economy ${ }^{1}$ has achieved rapid development, and it is one of the strongest and most active regions in Guangdong and even China. In 2019, the Pearl River Delta region's GDP was 8689.905 billion yuan, accounting for $80.5 \%$ of Guangdong Province. However, it is undeniable that the economic development within the Pearl River Delta region varies greatly. In 2019, the GDP of Shenzhen and Guangzhou were 2692.709 billion yuan and 2362.860 billion yuan respectively, ranking the top two in the Pearl River Delta, accounting for $30.9 \%$ and $27.2 \%$ of the Pearl River Delta respectively, and the sum total accounted for nearly $60 \%$. The Zhaoqing region, which ranked last, had only 224.88 billion yuan, accounting for only $2.6 \%$ of the Pearl River Delta.

The level of economic output depends on the efficiency of resource allocation, the market is an important way to optimize resource allocation, and the sustained economic growth can only be

The Pearl River Delta includes nine cities at the Pearl River Estuary: Guangzhou, Shenzhen, Zhuhai, Foshan, Huizhou, Dongguan, Zhongshan, Jiangmen, and Zhaoqing. achieved by improving market integration. Market segmentation is the opposite concept of market integration, which mainly refers to the obstacles to the free flow of resources among regions caused by the government's restrictions on the entry of academic resources into the local market or the flow of local resources to other places. Market segmentation hinders the formation of a regional unified market and reduces the efficiency of regional resource allocation.

Since Young studied the Chinese market segmentation in 2000, many scholars have participated in this research. The current academic research on market segmentation mainly focuses on three aspects. The first is to study whether there is market segmentation, to measure and analyze the extent and evolution trend of market segmentation. Young [1] and Zheng Yusheng [2] believe that the degree of market segmentation in China has tended to rise since the reform and opening up. $\mathrm{Li}$ Shantong [3], Gui Qihan [4], Qiu Feng [5], Kong Lingchi [6], Wang Jiankang [7] and other scholars refute the doubt that China's domestic commodity market tends to be fragmented, and they believe that although market segmentation still exists in 
China, the degree of market segmentation has been further converged, showing a downward trend, the degree of market integration is generally on the rise, and the degree of regional market segmentation has obvious spatial autocorrelation. The second is to study and analyze the reasons and motivations of market segmentation. Economic nationalization, local government competition, government intervention, local protection and fiscal decentralization policies have increased the level of market segmentation [7] [8]; the opening degree has a non-linear relationship with market segmentation [9]; the infrastructure construction and central transfer payments are effective means to break market segmentation [6]; the core of the inter-regional market segmentation is still the problem of relationship between the government and the market. The third is to study and analyze the impact of market segmentation on economic development. Based on evidence from the manufacturing industry, Xu Baochang [10] believes that market segmentation under certain conditions can promote the improvement of local enterprise productivity, which is in line with the interests of local economy and government officials to some extent. Wang Lei [11] constructs a provincial resource allocation efficiency measurement index based on total productivity and finds that the market segmentation is significantly negatively correlated with resource allocation efficiency. Song Donglin [12] believes that there is no regular relationship between market segmentation and economic growth, the western region shows a U-shaped relationship, the eastern and central regions show an inverted Ushaped relationship, and the northeastern region is not significant. In terms of regional market segmentation research, Bu Maoliang [13] studies the relationship between market non-integration (market segmentation) and economic growth in the Yangtze River Delta. Lin Zhipeng [14] believes that the degree of commodity market segmentation in the Pearl River Delta from 1999 to 2009 generally maintains a downward trend, and is lower than that in the Yangtze River Delta.

Summing up the above, most of the existing research on market segmentation focuses on the national level, and there are few studies on regions below the provincial level. The Pearl River Delta is one of the three most active economic regions in China and an important part of the Guangdong-Hong Kong-Macao Greater Bay region, and studying the status of its commodity market segmentation can provide reference for the formulation of regional economic policies in the
Pearl River Delta, Guangdong Province, and the Guangdong-Hong Kong-Macao Greater Bay region.

\section{RESEARCH METHODS AND DATA SOURCES}

The market segmentation index is one of the important indicators to measure the degree of local protectionism, reflecting the degree of market integration in a region. The measurement of market segmentation mainly includes five methods: trade flow method, production method, price method, business cycle method, and questionnaire survey method [15]. This article adopts the commonly used price index method that reflects the degree of market segmentation by relative price fluctuations, and selects the consumer price index of seven categories of commodities: service, food, clothing, medical and health supplies, transportation and communication, entertainment, education and culture, and residence 2 to calculate the commodity market segmentation index. The calculation formula is as follows:

- Calculate the absolute value of relative prices between $\mathrm{N}(\mathrm{N}-1)$ "city pairs" composed of each city and other cities: $\mathrm{i}$ and $\mathrm{j}$ respectively represent cities, $t$ represents the year, $\mathrm{k}$ represents the type of goods, $\mathrm{N}$ is the total number of cities, and $\mathrm{p}$ is the commodity consumer price index:

$$
\left|\Delta \mathrm{Q}_{\mathrm{ijt}}^{\mathrm{k} t}\right|=\left|\ln \left(\mathrm{p}_{\mathrm{it}}^{\mathrm{k}} / \mathrm{p}_{\mathrm{jt}}^{\mathrm{k}}\right)-\ln \left(\mathrm{p}_{\mathrm{it}-1}^{\mathrm{k}} / \mathrm{p}_{\mathrm{jt}-1}^{\mathrm{k}}\right)\right|
$$

- Given $t$ and $k$, find the mean value of all city

$$
\frac{\text { pairs }}{\left|\Delta Q_{t}^{k}\right|}=2 \sum_{i \neq j}\left|\Delta Q_{i j t}^{k}\right| / N(N-1)
$$

- Given $\mathrm{t}$ and $\mathrm{k}$, de-mean all $\left|\Delta \mathrm{Q}_{\mathrm{ij \textrm {t }}}^{\mathrm{k}}\right|$, $\mathrm{q}_{\mathrm{ijt}}^{\mathrm{k}}=\left|\Delta \mathrm{Q}_{\mathrm{ijt}}^{\mathrm{k}}\right|-\left|\Delta \overline{\mathrm{Q}}_{\mathrm{t}}^{\mathrm{k}}\right|$

- Calculate the variance var $\left(\mathrm{q}_{\mathrm{ijt}}\right)$ of all "city pairs" commodity category k year by year;

- Given i, calculate the arithmetic mean of all variances containing i year by year, that is, the market segmentation index of the city, $\operatorname{var}\left(\mathrm{q}_{\mathrm{it}}\right)=\frac{1}{\mathrm{~N}} \sum_{\mathrm{i} \neq \mathrm{j}} \operatorname{var}\left(\mathrm{q}_{\mathrm{ijt}}\right)$. The larger the value of $\operatorname{var}\left(\mathrm{q}_{\mathrm{it}}\right)$ is, the larger the commodity market segmentation index is,

Data on tobacco and wine, supplies, and daily necessities are incomplete. 
the more serious the segmentation of commodity market between this region and surrounding region is.

All the original data in this article come from "Guangdong Statistical Yearbook" (2001-2018).

\section{EMPIRICAL ANALYSIS}

\subsection{Analysis of Commodity Market Segmentation Index of Cities in the Pearl River Delta}

It can be seen from "Table 1" that from the average level of 18 years from 2000 to 2017, the commodity market segmentation index of Zhongshan, Zhuhai, and Huizhou is the highest, which is $3.26,3.21$ and 3.04 respectively, showing that the commodity market segmentation of these three cities is the most serious, and the economic development level of these three cities is also relatively backward in the region. Zhaoqing and Jiangmen have the lowest level of economic development, and the lowest level of commodity market segmentation at 2.63 and 2.71 respectively.
Guangzhou and Shenzhen, which have the highest level of economic development in the region, have moderate level of market segmentation. This shows that there is a certain correlation between the level of regional economic development and the level of commodity market segmentation. Specifically, the lower level of regional economic development in the region, the clearer the choice of commodity market segmentation attitude, and the government will often promote economic growth through commodity market segmentation and local protectionism. Regions with the highest level of regional economic development have the most neutral attitude towards commodity market segmentation. However, regions with a very low level of regional economic development have a positive correlation with the commodity market segmentation. These regions need appropriate market segmentation to promote economic development. As one of the regions with the highest degree of openness in the Pearl River Delta, Zhuhai is still in the stage of making up for the loss of internal segmentation through the benefits of foreign trade, and the phenomenon of commodity market segmentation is severe.

Table 1. Commodity market segmentation indexes of cities in the Pearl River Delta from 2000 to 2017

\begin{tabular}{|c|c|c|c|c|c|c|c|c|c|}
\hline & $\begin{array}{l}\text { Guangzho } \\
\mathrm{u}\end{array}$ & $\begin{array}{l}\text { Shenzhe } \\
\mathrm{n}\end{array}$ & Zhuhai & Foshan & $\begin{array}{l}\text { Huizho } \\
\text { u }\end{array}$ & $\begin{array}{l}\text { Donggua } \\
\mathrm{n}\end{array}$ & $\begin{array}{l}\text { Zhongsha } \\
\mathrm{n}\end{array}$ & $\begin{array}{l}\text { Jiangme } \\
\mathrm{n}\end{array}$ & $\begin{array}{l}\text { Zhaoqin } \\
\mathrm{g}\end{array}$ \\
\hline 2000 & 7.73 & 9.21 & 10.32 & 7.30 & 9.60 & 8.62 & 9.62 & 8.79 & 6.08 \\
\hline 2001 & 1.89 & 3.75 & 2.30 & 1.89 & 2.66 & 2.62 & 3.37 & 1.98 & 2.77 \\
\hline 2002 & 3.26 & 5.04 & 1.95 & 3.26 & 2.85 & 5.10 & 2.40 & 3.54 & 2.49 \\
\hline 2003 & 1.58 & 2.12 & 2.11 & 1.58 & 2.64 & 2.87 & 5.92 & 3.00 & 3.08 \\
\hline 2004 & 2.78 & 2.77 & 2.74 & 2.78 & 2.12 & 1.78 & 5.75 & 2.59 & 3.53 \\
\hline 2005 & 5.80 & 6.36 & 8.61 & 5.80 & 8.11 & 7.79 & 7.37 & 6.37 & 4.35 \\
\hline 2006 & 1.74 & 2.16 & 1.68 & 1.74 & 1.91 & 1.81 & 1.56 & 1.32 & 3.23 \\
\hline 2007 & 1.50 & 2.71 & 2.32 & 1.50 & 1.67 & 1.90 & 4.32 & 1.79 & 1.71 \\
\hline 2008 & 3.03 & 4.24 & 6.82 & 3.03 & 2.47 & 2.84 & 1.73 & 3.15 & 2.63 \\
\hline 2009 & 2.25 & 2.32 & 2.68 & 2.25 & 3.65 & 2.44 & 2.68 & 1.67 & 2.47 \\
\hline 2010 & 4.84 & 2.15 & 2.00 & 4.84 & 2.25 & 2.43 & 2.87 & 2.10 & 2.74 \\
\hline 2011 & 1.05 & 0.78 & 0.82 & 1.05 & 1.89 & 0.99 & 0.88 & 1.70 & 1.39 \\
\hline 2012 & 3.66 & 1.07 & 2.52 & 3.66 & 4.34 & 2.92 & 2.96 & 3.09 & 2.53 \\
\hline 2013 & 1.16 & 1.06 & 0.78 & 1.16 & 1.57 & 0.78 & 1.35 & 0.79 & 1.39 \\
\hline 2014 & 1.12 & 0.95 & 1.22 & 1.12 & 1.54 & 1.31 & 1.20 & 1.01 & 1.39 \\
\hline 2015 & 2.25 & 1.81 & 3.51 & 2.25 & 1.61 & 1.28 & 1.51 & 1.64 & 1.91 \\
\hline 2016 & 2.17 & 0.87 & 3.15 & 2.17 & 2.11 & 2.13 & 1.93 & 1.56 & 2.27 \\
\hline $\begin{array}{l}2017 \\
\text { Mean }\end{array}$ & $\begin{array}{l}1.72 \\
2.75 \\
\end{array}$ & $\begin{array}{l}1.16 \\
2.81 \\
\end{array}$ & $\begin{array}{l}2.27 \\
3.21 \\
\end{array}$ & $\begin{array}{l}1.72 \\
2.73 \\
\end{array}$ & $\begin{array}{l}1.75 \\
3.04 \\
\end{array}$ & $\begin{array}{l}2.12 \\
2.87\end{array}$ & $\begin{array}{l}1.33 \\
3.26 \\
\end{array}$ & $\begin{array}{l}2.68 \\
2.71 \\
\end{array}$ & $\begin{array}{l}1.31 \\
2.63 \\
\end{array}$ \\
\hline
\end{tabular}




\subsection{Evolution Trend of Commodity Market Segmentation in the Pearl River Delta}

\subsubsection{The Overall Evolution Trend of Commodity Market Segmentation in the Pearl River Delta}

It can be seen from "Figure 1" that the commodity market segmentation index of the Pearl River Delta from 2000 to 2017 showed an overall downward trend, with fluctuations in some specific years and a slight increase. In 2005, the ascensional range was relatively large. Specifically, the commodity market segmentation index of Pearl River Delta was the highest in 2000, reaching 8.59 , then it fell to 2.58 in 2001, and there was little fluctuation in the following four years. It reached a small peak in 2005 and increased to 6.73. With the issuance and implementation of the "Plan for the Coordinated Development of Urban Agglomeration in the Pearl River Delta" at the end of 2005, the commodity market segmentation index fell again. After the 2007 financial crisis, cities took measures to protect the local economy. In 2008, the market segmentation showed a trend of resurgence again. With the weakening of the impact of the financial tsunami, after 2009, the market segmentation index of Pearl River Delta fell again to the lowest value of 1.115 in 2013.

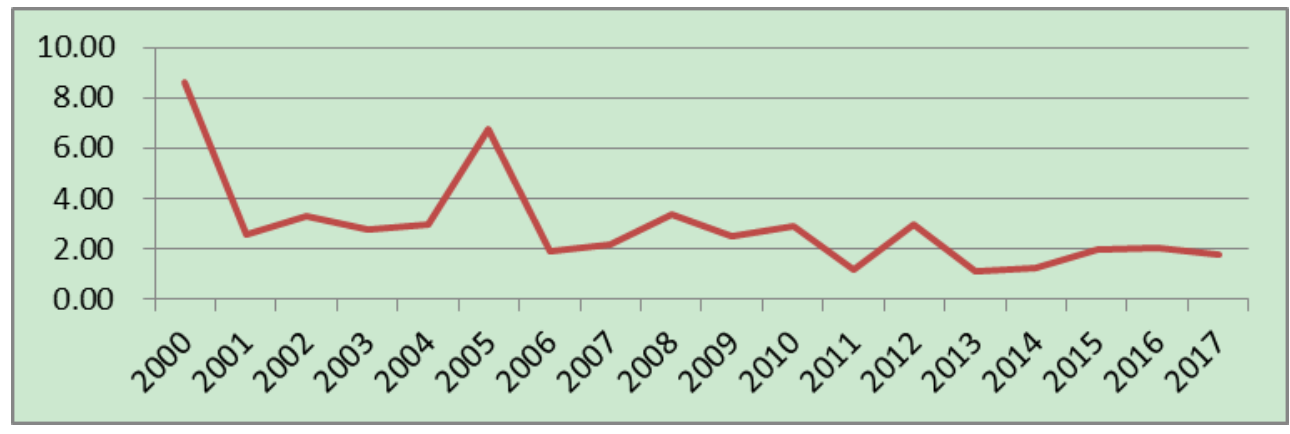

Figure 1 The overall evolution trend of commodity market segmentation in the Pearl River Delta from 2000 to 2017.

\subsubsection{Evolution Trend of Commodity Market Segmentation in Cities in the Pearl River Delta}

Judging from the situation of each city, the overall market segmentation index of each city tended to decline, which was basically consistent with the general trend of the Pearl River Delta except that some cities fluctuated greatly. Specifically, the market segmentation levels of Guangzhou, Zhuhai and Foshan fluctuated greatly. The continuous declination trend of Shenzhen was the most obvious, and the market segmentation index continued to decrease. ("Figure 2")

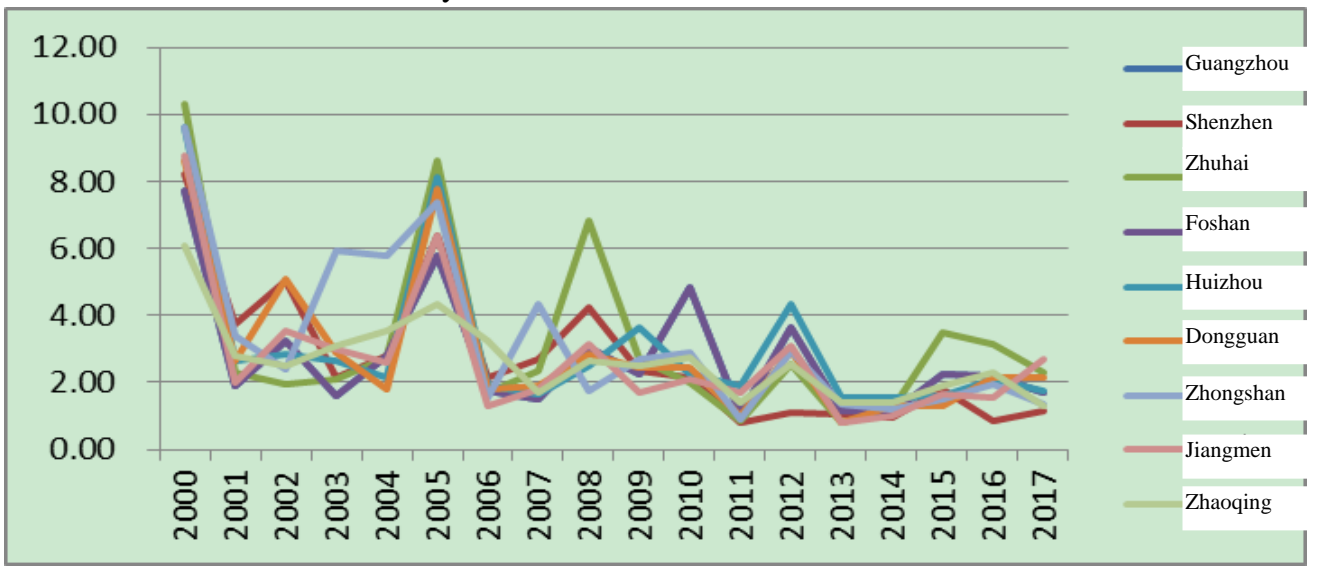

Figure 2 The evolution trend of the commodity market segmentation in cities in the Pearl River Delta from 2000 to 2017 . 


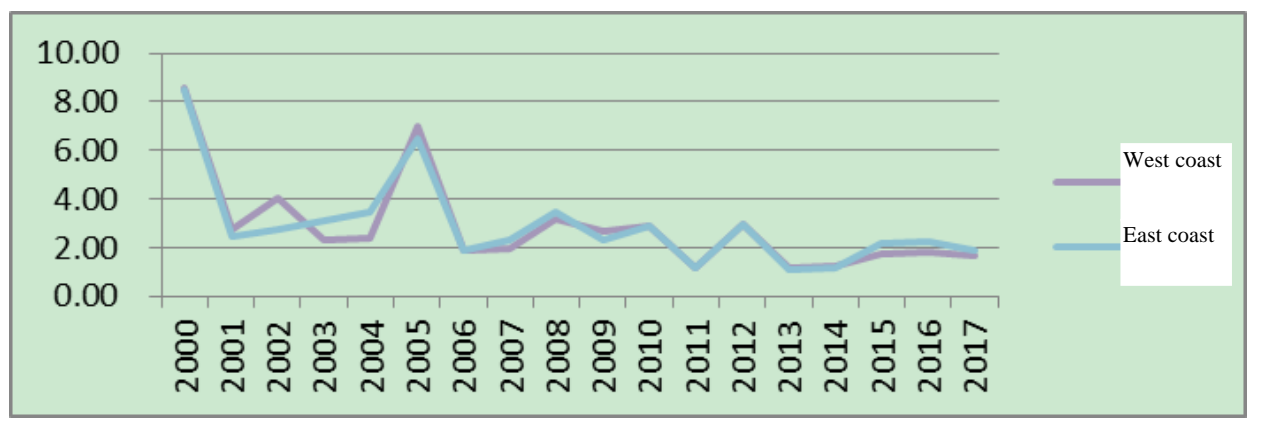

Figure 3 The evolution trend of the regional commodity market segmentation in the Pearl River Delta from 2000 to 2017.

\subsubsection{Evolution Trend of Commodity Market Segmentation in Various Regions of the Pearl River Delta}

From the perspective of the inner regions of the Pearl River Delta ("Figure 3"), from 2000 to 2006, the commodity market segmentation index on the east coast and west coast ${ }^{3}$ fluctuated greatly. From 2000 to 2002, the east coast market was more fragmented than the west coast. In 2003 and 2004, the west coast was more serious than the east coast. After 2006, with the development of the east coast regional economy, the proposal of the ShenzhenDongguan-Huizhou integration strategy, and the implementation of the "Planning Integration Cooperation Agreement of Shenzhen, Dongguan, and Huizhou", the east coast optimized the spatial layout and resource allocation, rationally laid out major infrastructure, and guided the development of industrial clusters. And as a result, the degree of market integration of east coast continued to increase, and the level and trend of market segmentation were consistent with those of the west coast. After 2014, the level of market integration in the east coast was significantly better than the west coast.

\section{CONCLUSION}

From the average level during the study period, the commodity markets of Zhongshan, Zhuhai and Huizhou in the Pearl River Delta were the most fragmented, and the Zhaoqing and Jiangmen markets were the least fragmented. From the perspective of evolutionary trends, the commodity market segmentation index of the Pearl River Delta showed an overall downward trend, with small fluctuations in

The east coast region includes the four cities of Guangzhou, Shenzhen, Huizhou and Dongguan on the east coast of the Pearl River Estuary. The west coast region includes the five cities of Zhuhai, Foshan, Jiangmen, Zhaoqing and Zhongshan on the west coast of the Pearl River Estuary. some specific years, and the overall market tended to be integrated. The evolution trend of the market segmentation level of internal regions and cities was basically consistent with the overall trend. Among them, the market segmentation level of Guangzhou, Zhuhai and Foshan changed greatly, and the continuous decline trend of Shenzhen was the most obvious. After 2006, the west coast market was more fragmented than the east coast.

Therefore, efforts should be made to make good use of the geographical proximity advantages of the Pearl River Delta regions, construct the Pearl River Estuary Urban Belt, actively promote the smooth flow of people, goods, capital and information in regions, improve the efficiency of regional resource allocation, weaken the partial unbalanced development caused by market segmentation, and realize the rationalization of professional division of labor and the development of economies of scale, thereby promoting the development of market integration in the Guangdong-Hong Kong-Macao Greater Bay Area.

\section{AUTHORS' CONTRIBUTIONS}

This paper is independently completed by Longfang Chen.

\section{REFERENCES}

[1] Young A. The razor's edge: Distortions and incremental reformin the People's Republic of China [J]. The Quarterly Journal of Economics, 2000, 115(4): 1091-1135.

[2] Zheng Yusheng, Li Chonggao. The Efficiency Loss of China's Regional Segmentation [J]. Social Sciences in China, 2003, (1): 64-72. (in Chinese) 
[3] Li Shantong, Hou Yongzhi, Liu Yunzhong. Investigation and Analysis of Local Protectionism Issues in China $[\mathrm{J}]$. Economic Research, 2004(11):78-85. (in Chinese)

[4] Gui Qihan, Chen Min, Lu Ming, Chen Zhao. China's Domestic Commodity Market Tends To Be Segmented or Integrated: An Analysis Based on the Relative Price Method [J]. World Economy, 2006, (2): 20-30. (in Chinese)

[5] Qiu Feng, Wang Zhengxin, Lin Yangyang, Sheng Wenwen, Wang Qian. Local Protectionism, Market Segmentation and Regional Industrial Structure Differentiation [J]. Collected Essays on Finance and Economics, 2015, (10): 103-112. (in Chinese)

[6] Kong Lingchi. Measurement of Chinese Market Segmentation and Analysis of Its Influencing Factors [J]. Journal of Zhengzhou University (Philosophy and Social Science Edition, 2019, (1): 59-128. (in Chinese)

[7] Wang Jiankang. The Spatial-Temporal Pattern and Influencing Factors of China's Interprovincial Market Segmentation [J]. Geographical Science, 2018, (12): 1988-1997. (in Chinese)

[8] Liu Xiaoyong, Li Zhen. An Empirical Study on Fiscal Decentralization and Regional Market Segmentation [J]. Research of Finance and Economics, 2008, (2): 88-98. (in Chinese)

[9] Gui Qihan, Chen Min, Lu Ming, Chen Zhao. China's Domestic Commodity Market Tends To Be Segmented or Integrated: An Analysis Based on the Relative Price Method [J]. World Economy, 2007, (1): 20-30. (in Chinese)

[10] Xu Baochang, Xie Jianguo. Market Segmentation and Enterprise Productivity: Evidence from Chinese Manufacturing Enterprises [J]. World Economy, 2016, (1): 95122. (in Chinese)

[11] Wang Lei, Wang Heng. Market Segmentation and Regional Resource Allocation Efficiency [J]. Commercial Research, 2015, (458): 19-25. (in Chinese)

[12] Song Donglin, Fan Xin, Zhao Xinyu. Regional Development Strategy, Market Segmentation and Economic Growth - An Empirical Analysis Based on the Relative Price Index
Method [J]. Finance \& Trade Economics, 2014, (8): 115-126. (in Chinese)

[13] Bu Maoliang, Gao Yanyan, Zhang Sanfeng. Market Integration and Economic Growth: An Empirical Study Based on the Yangtze River Delta [J]. Zhejiang Social Sciences, 2010, (6): 11-17. (in Chinese)

[14] Lin Zhipeng. An Empirical Study on the Status Quo of the Commodity Market Segmentation in the Pearl River Delta [J]. Journal of Guangdong Business College, 2011, (6): 49-55. (in Chinese)

[15] Yu Donghua, Liu Yun. Measurement and Identification of Local Protection and Market Segmentation - A Literature Review Based on Methodology [J]. World Economic Papers, 2009,(1):81-93. (in Chinese) 